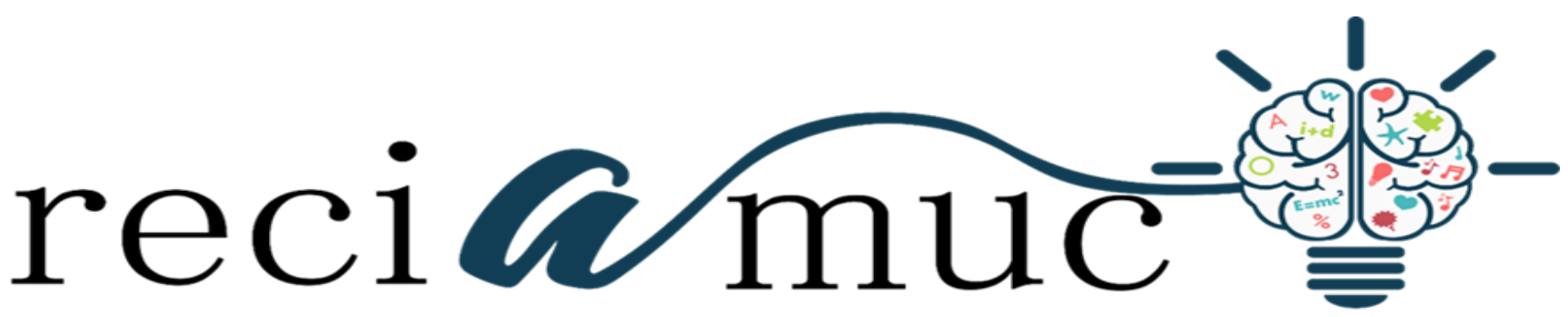

Revista cientifica de investigación actualización del mundo de las ciencias

\begin{abstract}
Alicia Cumanda Solano Barona a ; Deborah Denisse Jaramillo Cañadas ${ }^{\text {b; }}$ Karen
\end{abstract} Gissela Moreira Cusme ${ }^{\text {c; }}$ Karym Gabriela Jácome Vera ${ }^{d}$

Desarrollo embriológico humano

Human embryological development

Revista Científica de Investigación actualización del mundo de las Ciencias. Vol. 3 núm., 1, enero, ISSN: 2588-0748, 2018, pp. 22-40

DOI: $10.26820 / \mathrm{reciamuc/3.(1).enero.2019.22-40}$

URL: http://reciamuc.com/index.php/RECIAMUC/article/view/215

Código UNESCO: 3205 Medicina Interna

Tipo de Investigación: Artículo de Revisión

Editorial Saberes del Conocimiento

Recibido: 10/12/2018

Aceptado: 20/01/2019

Publicado: 30/01/2019

Correspondencia: director@ reciamuc.com
a. Médico; Guayaquil; Ecuador.
b. Médico; Guayaquil; Ecuador.
c. Médico; Guayaquil; Ecuador.
d. Médico; Guayaquil; Ecuador. 


\section{Desarrollo embriológico humano}

Vol. 3, núm. 1., (2019)

Alicia Cumanda Solano Barona; Deborah Denisse Jaramillo Cañadas; Karen Gissela Moreira Cusme; Karym Gabriela Jácome Vera

\section{RESUMEN}

El interés en el desarrollo humano está muy extendido en gran medida gracias a la intriga sobre nuestros inicios y un deseo de mejorar la calidad de vida humana. El proceso por el cual un bebé se desarrolla a partir de una célula es milagroso y pocos eventos son más emocionantes que un nacimiento humano. El desarrollo humano es un proceso continuo que comienza cuando un óvulo es fertilizado por un espermatozoide, la división celular, el crecimiento, la diferenciación e incluso la muerte celular, transforman el óvulo fertilizado en un ser humano multicelular. Aunque importantes cambios madurativos continúan ocurriendo durante el período postnatal (infancia, niñez, adolescencia e incluso la edad adulta), la formación de los sistemas de órganos ocurre entre la fertilización y el nacimiento, el período prenatal. Los objetivos de este trabajo es presentar los principios de la embriogénesis que están siendo utilizados para diagnosticar, corregir y, en última instancia, prevenir malformaciones congénitas y defectos de nacimiento. La clonación de todo el espectro de genes humanos, así como el desarrollo continuo de los métodos moleculares para prevenir las malformaciones congénitas han revolucionado todo el campo de embriología moderna. La mayoría de estas investigaciones se centrarán en las primeras ocho semanas de vida (conocido como el período embrionario) cuando los sistemas de órganos se desarrollan. Trabajos adicionales presentan brevemente la maduración fetal, el parto y el neonato.

Palabras Claves: Embrión; Genética; Desarrollo Embrionario; Células. 


\title{
Desarrollo embriológico humano
}

Vol. 3, núm. 1., (2019)

Alicia Cumanda Solano Barona; Deborah Denisse Jaramillo Cañadas; Karen Gissela Moreira Cusme; Karym Gabriela Jácome Vera

\begin{abstract}
The interest in human development is greatly extended thanks to the intrigue about our beginnings and a desire to improve the quality of human life. The process by which a baby develops from a cell is miraculous and few events are more exciting than a human birth. Human development is a continuous process that begins when an egg is fertilized by a sperm, cell division, growth, differentiation and even cell death, transform the fertilized egg into a multicellular human being. Although important maturational changes continue to occur during the postnatal period (childhood, childhood, adolescence and even adulthood), the formation of organ systems occurs between fertilization and birth, the prenatal period. The objectives of this work is to present the principles of embryogenesis that are being used to diagnose, correct and, ultimately, prevent congenital malformations and birth defects. The cloning of the entire spectrum of human genes, as well as the continued development of molecular methods to prevent congenital malformations have revolutionized the entire field of modern embryology. Most of these investigations will focus on the first eight weeks of life (known as the embryonic period) when organ systems develop. Additional works briefly present the fetal maturation, the birth and the newborn.
\end{abstract}

Key Words: Embryo; Genetics; Embryonic development; Cells. 


\section{Desarrollo embriológico humano}

Vol. 3, núm. 1., (2019)

Alicia Cumanda Solano Barona; Deborah Denisse Jaramillo Cañadas; Karen Gissela Moreira Cusme; Karym Gabriela Jácome Vera

\section{Introducción.}

La biología del desarrollo y la embriología humana han seguido cursos convergentes desde principios de los años noventa. La embriología humana es una antigua disciplina, con raíces que se remontan a la época de Aristóteles y algunos de los grandes anatomistas medievales. Leonardo da Vinci produjo una extensa serie de dibujos de aspectos de la embriología humana (O`Malley \& Saunders, 1982). La producción de embriones seccionados en serie y la formación de reconstrucciones tridimensionales de todo los embriones o sistemas de órganos individuales basados en placas de cera dieron como resultado la primera comprensión de la anatomía detallada de embriones humanos en diversas etapas de su desarrollo

El desarrollo embrionario se puede dividir en diferentes fases de desarrollo como cada proceso de desarrollo biológico, el desarrollo embriológico es un proceso en el tiempo y como tales etapas visibles aparecen como un proceso continuo en el tiempo, estas etapas y fases están en hecho producido artificialmente por el observador. Por lo tanto, el observador debe ser consciente de los criterios que él o ella usa para diferenciar las diversas fases.

Cuando miramos la planta en desarrollo, por ejemplo, se puede ver que crece de acuerdo con un patrón temporal particular que está estructurado por cambios morfológicos y funcionales. Estas fases se han clasificado en función de estos cambios morfológicos y funcionales. El término "fase" se utiliza para definir y describir un período de tiempo durante el cual un proceso se lleva a cabo. En la vida vegetal, por ejemplo, podemos discernir la germinación, el crecimiento y el florecimiento como procesos claramente diferentes y usamos un término particular para cada fase. Cada proceso (germinación, crecimiento y floración) representa un 


\section{Desarrollo embriológico humano}

Vol. 3, núm. 1., (2019)

Alicia Cumanda Solano Barona; Deborah Denisse Jaramillo Cañadas; Karen Gissela Moreira Cusme; Karym Gabriela Jácome Vera

aspecto particular del desarrollo de la planta resultando en particular productos vegetales o partes de plantas. Sin embargo, la diferenciación de las fases no es solo un resultado de la observación, también tiene una contraparte en el proceso de conceptualización en la mente humana: es decir, se reconoce un grupo de fenómenos como pertenecientes a un proceso particular. Los cambios en los procesos descritos determinan si el desarrollo está en una fase u otra, y los fenómenos visibles que pertenecen a ciertas etapas pueden considerarse como pertenecientes a una fase de desarrollo más amplia. Por lo tanto, una fase puede cubrir diferentes etapas.

El desarrollo humano es uno de los temas más emocionantes para estudiar no solo como estudiante de medicina, sino también para la comprensión fundamental del cuerpo humano. De todos los problemas de salud en medicina, fertilidad y reproducción es un tema que afectará a todos. Este trabajo será desarrollado brevemente a través de conceptos biológicos claves en humanos.

Embriología básica se enseña habitualmente en la secuencia cronológica de los eventos. Estos eventos son la base para comprender las anomalías congénitas que encontramos en el feto, y ayuda explicar las relaciones con otras preocupaciones del sistema orgánico. A continuación se muestra una sinopsis de algunos de los Pasos críticos en la embriogénesis desde la base anatómica en lugar de la molecular.

\section{Metodología.}

La revisión se ha centrado en textos, documentos y artículos científicos publicados disponibles en la web, considerando que aquella herencia de la globalización nos permite acceder a mayor y mejor información a través de las herramientas tecnológicas. Los criterios de inclusión 


\section{Desarrollo embriológico humano}

Vol. 3, núm. 1., (2019)

Alicia Cumanda Solano Barona; Deborah Denisse Jaramillo Cañadas; Karen Gissela Moreira Cusme; Karym Gabriela Jácome Vera

se basaron en publicaciones del habla hispana e inglesa y visible en bases de datos que nos aportaron en la historia y evolución de investigación. El motor de búsqueda ha sido herramientas académicas de la web que direccionan específicamente a archivos con validez y reconocimiento científico, descartando toda información no confirmada o sin las respectivas referencias bibliográficas.

\section{Resultados.}

A lo largo de este trabajo, se expresaran las edades embrionarias y fetales en términos de semanas desde la fecundación, comúnmente llamadas concepción. El período de tiempo requerido para el desarrollo completo de un feto en el útero se conoce como gestación (gestare $=$ "llevar"). Se puede subdividir en distintos períodos gestacionales. Las primeras 2 semanas de desarrollo prenatal se denominan etapas preembrionarias. Un ser humano en desarrollo se conoce como un embrión durante las semanas 3-8, y un feto desde la novena semana de gestación hasta el nacimiento. En esta sección, cubriremos las etapas pre-embrionarias y embrionarias del desarrollo, que se caracterizan por la división celular, la migración y la diferenciación. Al final del período embrionario, todos los sistemas de órganos están estructurados de forma rudimentaria, aunque los órganos en sí mismos no son funcionales o solo son semifuncionales.

\section{Desarrollo Embrionario Preimplantación}

Después de la fertilización, el cigoto y sus membranas asociadas, denominadas en conjunto como conceptus, continúan proyectándose hacia el útero mediante peristalsis y latidos de los cilios. Durante su viaje hacia el útero, el cigoto sufre cinco o seis divisiones celulares mitóticas rápidas. Aunque cada división produce más células, no aumenta el volumen total del 


\section{Desarrollo embriológico humano}

Vol. 3, núm. 1., (2019)

Alicia Cumanda Solano Barona; Deborah Denisse Jaramillo Cañadas; Karen Gissela Moreira Cusme; Karym Gabriela Jácome Vera

concepto. Cada célula hija producida por escisión se llama blastómero (blastos = "germen", en el sentido de una semilla o brote).

Aproximadamente 3 días después de la fertilización, un conceptus de 16 células llega al útero. Las células que se habían agrupado de forma flexible ahora están compactadas y se parecen más a una masa sólida. El nombre que se le da a esta estructura es la mórula (mórula = "mora pequeña") (Lagman, 2010). Una vez dentro del útero, el conceptus flota libremente por varios días más. Continúa dividiéndose, creando una bola de aproximadamente 100 células y consumiendo secreciones endometriales nutritivas llamadas leche uterina, mientras que el revestimiento uterino se espesa. La bola de células ahora estrechamente ligadas comienza a secretar líquido y se organiza alrededor de una cavidad llena de líquido, el blastocoel . En esta etapa de desarrollo, el concepto se conoce como un blastocisto. Dentro de esta estructura, un grupo de células se forma en una masa celular interna, que está destinada a convertirse en embrión. Las células que forman la capa externa se llaman trofoblastos (trophe = "para alimentar" o "para nutrir"). Estas células se desarrollarán en el saco coriónico y la porción fetal de la placenta (el órgano de intercambio de nutrientes, desechos y gases entre la madre y la cría en desarrollo).

La masa interna de las células embrionarias es totipotente durante esta etapa, lo que significa que cada célula tiene el potencial de diferenciarse en cualquier tipo de célula en el cuerpo humano. La totipotencia dura solo unos pocos días antes de que los destinos de las células se establezcan como precursores de un linaje específico de células. 


\section{Desarrollo embriológico humano}

Vol. 3, núm. 1., (2019)

Alicia Cumanda Solano Barona; Deborah Denisse Jaramillo Cañadas; Karen Gissela Moreira Cusme; Karym Gabriela Jácome Vera

\section{Implantación}

Al final de la primera semana, el blastocisto entra en contacto con la pared uterina y se adhiere a ella, incrustándose en el revestimiento uterino a través de las células trofoblásticas (Flores, 2009). Así comienza el proceso de implantación, que señala el final de la etapa de desarrollo preembrionario (Figura 1). La implantación puede ir acompañada de hemorragias leves. El blastocisto generalmente se implanta en el fondo del útero o en la pared posterior. Sin embargo, si el endometrio no está completamente desarrollado y listo para recibir el blastocisto, el blastocisto se desprenderá y encontrará un lugar mejor. Un porcentaje significativo (50-75 por ciento) de blastocistos no se implanta; cuando esto ocurre, el blastocisto se elimina con el endometrio durante la menstruación. La alta tasa de fracaso de la implantación es una de las razones por las que el embarazo generalmente requiere varios ciclos de ovulación para lograrlo (Barron, 1944).

\section{Figura 1. Periodo pre-embrionario}

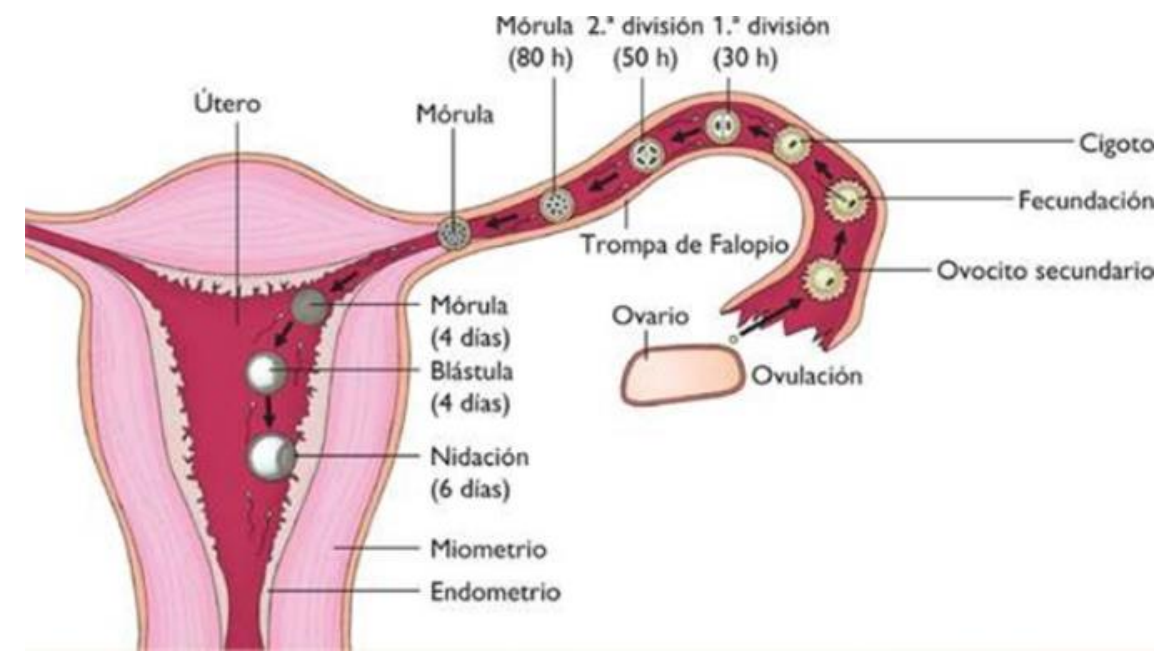

Fuente: SlideShare 


\section{Desarrollo embriológico humano}

Vol. 3, núm. 1., (2019)

Alicia Cumanda Solano Barona; Deborah Denisse Jaramillo Cañadas; Karen Gissela Moreira Cusme; Karym Gabriela Jácome Vera

Cuando la implantación es exitosa y el blastocisto se adhiere al endometrio, las células superficiales del trofoblasto se fusionan entre sí, formando el sincitiotrofoblasto, un cuerpo multinucleado que digiere las células endometriales para asegurar firmemente el blastocisto a la pared uterina. En respuesta, la mucosa uterina se reconstruye y envuelve el blastocisto. El trofoblasto secreta gonadotropina coriónica humana (hCG), una hormona que dirige el cuerpo lúteo para sobrevivir, aumentar de tamaño y continuar produciendo progesterona y estrógeno para suprimir la menstruación (Scott, 2003). Estas funciones de hCG son necesarias para crear un entorno adecuado para el embrión en desarrollo. Como resultado de este aumento de la producción, la hCG se acumula en el torrente sanguíneo materno y se excreta en la orina. La implantación se completa a mediados de la segunda semana. Apenas unos días después de la implantación, el trofoblasto ha secretado suficiente hCG para una prueba de embarazo de orina en casa para dar un resultado positivo.

La mayoría de las veces, un embrión se implanta dentro del cuerpo del útero en un lugar que puede ayudar al crecimiento y al desarrollo, sin embargo, en uno o dos por ciento de los casos, el embrión se implanta fuera del útero (un embarazo ectópico) o en una región del útero que puede crear complicaciones para el embarazo. Si el embrión se implanta en la parte inferior del útero, la placenta puede crecer potencialmente sobre la abertura del cuello uterino, una afección llamada placenta previa.

\section{Desarrollo del embrión}

En la gran mayoría de los embarazos ectópicos, el embrión no completa su viaje al útero y se implanta en la trompa uterina, lo que se conoce como un embarazo tubárico. Sin embargo, 


\section{Desarrollo embriológico humano}

Vol. 3, núm. 1., (2019)

Alicia Cumanda Solano Barona; Deborah Denisse Jaramillo Cañadas; Karen Gissela Moreira Cusme; Karym Gabriela Jácome Vera

también hay embarazos ectópicos ováricos (en los cuales el óvulo nunca salió del ovario) y embarazos ectópicos abdominales (en los cuales un óvulo se "perdió" en la cavidad abdominal durante la transferencia del ovario al tubo uterino, o en el cual un embrión de un embarazo de trompas reimplantado en el abdomen). Una vez en la cavidad abdominal, un embrión puede implantarse en cualquier estructura bien vascularizada: la cavidad rectouterina (bolsa de Douglas), el mesenterio de los intestinos y el omento mayor son algunos sitios comunes (Alarcon \& Marikawa, 2003).

Los embarazos de trompas pueden ser causados por tejido cicatricial dentro del tubo después de una infección bacteriana de transmisión sexual. El tejido cicatricial impide el avance del embrión hacia el útero, en algunos casos "engancha" el embrión y, en otros casos, bloquea completamente el tubo. Aproximadamente la mitad de los embarazos de trompas se resuelven espontáneamente. La implantación en un tubo uterino causa sangrado, que parece estimular las contracciones del músculo liso y la expulsión del embrión. En los casos restantes, es necesaria la intervención médica o quirúrgica. Si se detecta un embarazo ectópico temprano, el desarrollo del embrión se puede detener con la administración del metotrexato, un fármaco citotóxico que inhibe el metabolismo del ácido fólico. Si el diagnóstico es tarde y el tubo uterino ya está roto, la reparación quirúrgica es esencial.

Incluso si el embrión ha encontrado con éxito su camino hacia el útero, no siempre se implanta en una ubicación óptima (el fondo o la pared posterior del útero). Se puede producir una placenta previa si un embrión se implanta cerca del orificio interno del útero (la abertura interna del cuello uterino). A medida que el feto crece, la placenta puede cubrir parcial o completamente la abertura del cuello uterino. Aunque ocurre en solo el 0.5 por ciento de los 


\section{Desarrollo embriológico humano}

Vol. 3, núm. 1., (2019)

Alicia Cumanda Solano Barona; Deborah Denisse Jaramillo Cañadas; Karen Gissela Moreira Cusme; Karym Gabriela Jácome Vera

embarazos, la placenta previa es la causa principal de hemorragia anteparto (sangrado vaginal profuso después de la semana 24 de embarazo, pero antes del parto).

\section{Membranas embrionarias}

Durante la segunda semana de desarrollo, con el embrión implantado en el útero, las células dentro del blastocisto comienzan a organizarse en capas. Algunos crecen para formar las membranas extraembrionarias necesarias para sostener y proteger el embrión en crecimiento: el amnios, el saco vitelino, los alantos y el corion. Al comienzo de la segunda semana, las células de la masa celular interna se forman en un disco de dos capas de células embrionarias, y un espacio (la cavidad amniótica) se abre entre ella y el trofoblasto. Las células de la capa superior del disco (el epiblasto) se extienden alrededor de la cavidad amniótica, creando un saco membranoso que se forma en el amnios al final de la segunda semana (Moore, 2001). El amnios se llena con líquido amniótico y eventualmente crece para rodear el embrión. Al principio del desarrollo, el líquido amniótico consiste casi completamente en un filtrado del plasma materno, pero cuando los riñones del feto comienzan a funcionar aproximadamente a la octava semana, agregan orina al volumen de líquido amniótico. Flotando dentro del líquido amniótico, el embrión, y luego el feto, está protegido del trauma y los rápidos cambios de temperatura. Puede moverse libremente dentro del líquido y puede prepararse para tragar y respirar fuera del útero.

En el lado ventral del disco embrionario, opuesto al amnios, las células en la capa inferior del disco embrionario (el hipoblasto) se extienden hacia la cavidad del blastocisto y forman un saco vitelino. El saco vitelino suministra algunos nutrientes absorbidos por el trofoblasto y también proporciona circulación de sangre primitiva al embrión en desarrollo durante la segunda 


\section{Desarrollo embriológico humano}

Vol. 3, núm. 1., (2019)

Alicia Cumanda Solano Barona; Deborah Denisse Jaramillo Cañadas; Karen Gissela Moreira Cusme; Karym Gabriela Jácome Vera

y tercera semana de desarrollo. Cuando la placenta se hace cargo de nutrir el embrión aproximadamente en la semana 4, el tamaño del saco vitelino se ha reducido considerablemente y su función principal es servir como fuente de células sanguíneas y células germinales (células que darán lugar a los gametos). Durante la semana 3, se desarrolla una evacuación similar a un dedo del saco vitelino hacia la alantois, un conducto excretor primitivo del embrión que se convertirá en parte de la vejiga urinaria. Juntos, los tallos del saco vitelino y alantoides establecen la estructura externa del cordón umbilical.

La última de las membranas extraembrionarias es el corion, que es la membrana que rodea a todas las demás. El desarrollo del corion se discutirá con más detalle en breve, en relación con el crecimiento y desarrollo de la placenta.

\section{Embriogénesis}

Cuando comienza la tercera semana de desarrollo, el disco de células de dos capas se convierte en un disco de tres capas a través del proceso de gastrulación, durante el cual las células pasan de la totipotencia a la multipotencia. El embrión, que toma la forma de un disco de forma ovalada, forma una hendidura llamada raya primitiva a lo largo de la superficie dorsal del epiblasto. Un nodo en el extremo caudal o "cola" de la línea primitiva emite factores de crecimiento que hacen que las células se multipliquen y migren. Las células migran hacia y a través de la línea primitiva y luego se mueven lateralmente para crear dos nuevas capas de células. La primera capa es el endodermo, una lámina de células que desplaza el hipoblasto y se encuentra adyacente al saco vitelino. La segunda capa de células se llena como la capa media, o 


\section{Desarrollo embriológico humano}

Vol. 3, núm. 1., (2019)

Alicia Cumanda Solano Barona; Deborah Denisse Jaramillo Cañadas; Karen Gissela Moreira Cusme; Karym Gabriela Jácome Vera

mesodermo. Las células del epiblasto que permanecen (no habiendo migrado a través de la veta primitiva) se convierten en el ectodermo (Larsen, 2001).

Cada una de estas capas germinales se desarrollará en estructuras específicas en el embrión. Mientras que el ectodermo y el endodermo forman láminas epiteliales estrechamente conectadas, las células mesodérmicas están menos organizadas y existen como una comunidad celular débilmente conectada. El ectodermo da origen a linajes celulares que se diferencian para convertirse en el sistema nervioso central y periférico, los órganos sensoriales, la epidermis, el cabello y las uñas. Las células mesodérmicas finalmente se convierten en el esqueleto, los músculos, el tejido conectivo, el corazón, los vasos sanguíneos y los riñones. El endodermo continúa formando el revestimiento epitelial del tracto gastrointestinal, el hígado y el páncreas, así como los pulmones.

\section{Desarrollo de la placenta}

Durante las primeras semanas de desarrollo, las células del endometrio, denominadas células deciduales, nutren el embrión naciente. Durante las semanas prenatales 4-12, la placenta en desarrollo asume gradualmente el papel de alimentar al embrión, y las células deciduales ya no son necesarias. La placenta madura está compuesta por tejidos derivados del embrión, así como por los tejidos maternos del endometrio. La placenta se conecta al concepto a través del cordón umbilical, que transporta sangre desoxigenada y desechos del feto a través de dos arterias umbilicales; Los nutrientes y el oxígeno se transportan de la madre al feto a través de la vena umbilical única. El cordón umbilical está rodeado por el amnios, y los espacios dentro del cordón 


\section{Desarrollo embriológico humano}

Vol. 3, núm. 1., (2019)

Alicia Cumanda Solano Barona; Deborah Denisse Jaramillo Cañadas; Karen Gissela Moreira Cusme; Karym Gabriela Jácome Vera

que rodea los vasos sanguíneos se llenan con la gelatina de Wharton, un tejido conjuntivo mucoso.

La porción materna de la placenta se desarrolla a partir de la capa más profunda del endometrio, la decidua basal. Para formar la porción embrionaria de la placenta, el sincitiotrofoblasto y las células subyacentes del trofoblasto (células citotrofoblastas) comienzan a proliferar junto con una capa de células mesodermo extraembriónicas. Estos forman la membrana coriónica, que envuelve todo el concepto como el corion. La membrana coriónica forma estructuras similares a los dedos llamadas vellosidades coriónicas que se introducen en el endometrio como las raíces de los árboles, formando la porción fetal de la placenta. Las células del citotrofoblasto perforan las vellosidades coriónicas, se adentran en el endometrio y remodelan los vasos sanguíneos maternos para aumentar el flujo sanguíneo materno que rodea las vellosidades. Mientras tanto, las células mesenquimales fetales derivadas del mesodermo llenan las vellosidades y se diferencian en vasos sanguíneos, incluidos los tres vasos sanguíneos umbilicales que conectan el embrión con la placenta en desarrollo.

La placenta se desarrolla a lo largo del período embrionario y durante las primeras semanas del período fetal; La placentación se completa en las semanas 14-16. Como órgano completamente desarrollado, la placenta proporciona nutrición y excreción, respiración y función endocrina (Tabla 1 y Figura 9). Recibe sangre del feto a través de las arterias umbilicales. Los capilares en las vellosidades coriónicas filtran los desechos fetales de la sangre y devuelven la sangre limpia y oxigenada al feto a través de la vena umbilical. Los nutrientes y el oxígeno se transfieren de la sangre materna que rodea las vellosidades a través de los capilares y al torrente sanguíneo fetal. Algunas sustancias se mueven a través de la placenta por simple difusión. El 


\section{Desarrollo embriológico humano}

Vol. 3, núm. 1., (2019)

Alicia Cumanda Solano Barona; Deborah Denisse Jaramillo Cañadas; Karen Gissela Moreira Cusme; Karym Gabriela Jácome Vera

oxígeno, el dióxido de carbono y cualquier otra sustancia soluble en lípidos toman esta ruta. Otras sustancias se mueven a través de la difusión facilitada. Esto incluye la glucosa soluble en agua. El feto tiene una gran demanda de aminoácidos y hierro, y esas sustancias se mueven a través de la placenta mediante transporte activo.

La sangre materna y fetal no se mezcla porque las células sanguíneas no pueden moverse a través de la placenta. Esta separación impide que las células T citotóxicas de la madre alcancen y luego destruyan al feto, que contiene antígenos "no propios". Además, garantiza que los glóbulos rojos fetales no entren en la circulación de la madre y desencadenen el desarrollo de anticuerpos (si llevan antígenos "no propios"), al menos hasta las etapas finales del embarazo o el parto. Esta es la razón por la que, incluso en ausencia de tratamiento preventivo, una Rhmadre no desarrolla anticuerpos que podrían causar una enfermedad hemolítica en su primer feto $\mathrm{Rh}+$.

Aunque las células sanguíneas no se intercambian, las vellosidades coriónicas proporcionan una amplia área de superficie para el intercambio bidireccional de sustancias entre la sangre materna y fetal. La tasa de cambio aumenta a lo largo de la gestación a medida que las vellosidades se adelgazan y se ramifican cada vez más. La placenta es permeable a sustancias fetotóxicas solubles en lípidos: alcohol, nicotina, barbitúricos, antibióticos, ciertos patógenos y muchas otras sustancias que pueden ser peligrosas o fatales para el embrión o el feto en desarrollo. Por estas razones, las mujeres embarazadas deben evitar las sustancias fetotóxicas. El consumo de alcohol por parte de las mujeres embarazadas, por ejemplo, puede dar lugar a una serie de anomalías denominadas trastornos del espectro alcohólico fetal (FASD). Estos incluyen 


\section{Desarrollo embriológico humano}

Vol. 3, núm. 1., (2019)

Alicia Cumanda Solano Barona; Deborah Denisse Jaramillo Cañadas; Karen Gissela Moreira Cusme; Karym Gabriela Jácome Vera

malformaciones de órganos y faciales, así como trastornos cognitivos y de comportamiento (Polin, 1999).

\section{Organogénesis}

Tras la gastrulación, se desarrollan rudimentos del sistema nervioso central a partir del ectodermo en el proceso de neurulación. Los tejidos neuroectodérmicos especializados a lo largo del embrión se engrosan en la placa neural. Durante la cuarta semana, los tejidos a cada lado de la placa se pliegan hacia arriba formando un pliegue neural. Los dos pliegues convergen para formar el tubo neural. El tubo se encuentra sobre una notocorda derivada del mesodermo en forma de varilla, que eventualmente se convierte en el núcleo pulposo de los discos intervertebrales. Las estructuras tipo bloque llamadas somitas se forman a ambos lados del tubo, y finalmente se diferencian en el esqueleto axial, el músculo esquelético y la dermis. Durante la cuarta y quinta semanas, el tubo neural anterior se dilata y se subdivide para formar vesículas que se convertirán en las estructuras cerebrales.

El folato, una de las vitaminas B, es importante para el desarrollo saludable del tubo neural. Una deficiencia de folato materno en las primeras semanas de embarazo puede causar defectos del tubo neural, incluida la espina bífida, un defecto de nacimiento en el que el tejido espinal sobresale a través de la columna vertebral del recién nacido, que no se ha cerrado completamente. Un defecto del tubo neural más grave es la anencefalia, una ausencia parcial o completa de tejido cerebral.

El embrión, que comienza como una lámina plana de células, comienza a adquirir una forma cilíndrica a través del proceso de plegamiento embrionario. El embrión se pliega 


\section{Desarrollo embriológico humano}

Vol. 3, núm. 1., (2019)

Alicia Cumanda Solano Barona; Deborah Denisse Jaramillo Cañadas; Karen Gissela Moreira Cusme; Karym Gabriela Jácome Vera

lateralmente y nuevamente en cada extremo, formando una forma de $\mathrm{C}$ con distintos extremos de cabeza y cola. El embrión envuelve una porción del saco vitelino, que sobresale con el cordón umbilical de lo que se convertirá en el abdomen. El plegado esencialmente crea un tubo, llamado intestino primitivo, que está revestido por el endodermo. El saco amniótico, que estaba sentado sobre el embrión plano, envuelve al embrión cuando se pliega.

Dentro de las primeras 8 semanas de gestación, un embrión en desarrollo establece las estructuras rudimentarias de todos sus órganos y tejidos del ectodermo, mesodermo $\mathrm{y}$ endodermo. Este proceso se llama organogénesis.

Al igual que el sistema nervioso central, el corazón también comienza su desarrollo en el embrión como una estructura tubular, conectada a través de los capilares a las vellosidades coriónicas. Las células del corazón primitivo en forma de tubo son capaces de conducción y contracción eléctrica. El corazón comienza a latir a principios de la cuarta semana, aunque en realidad no bombea sangre embrionaria hasta una semana después, cuando el hígado de gran tamaño ha comenzado a producir glóbulos rojos. (Esta es una responsabilidad temporal del hígado embrionario que asumirá la médula ósea durante el desarrollo fetal). Durante las semanas 4 a 5, se forman las cavidades oculares, aparecen las yemas de las extremidades y se forman los rudimentos del sistema pulmonar.

Durante la sexta semana, comienzan a ocurrir movimientos no controlados de las extremidades fetales. El sistema gastrointestinal se desarrolla demasiado rápido para que el abdomen embrionario se acomode, y los intestinos se enrollan temporalmente en el cordón umbilical. Las manos y los pies en forma de paleta desarrollan dedos y dedos de los pies por el 


\section{Desarrollo embriológico humano}

Vol. 3, núm. 1., (2019)

Alicia Cumanda Solano Barona; Deborah Denisse Jaramillo Cañadas; Karen Gissela Moreira Cusme; Karym Gabriela Jácome Vera

proceso de apoptosis (muerte celular programada), que hace que los tejidos entre los dedos se desintegren. Para la semana 7, la estructura facial es más compleja e incluye fosas nasales, orejas externas y lentes. Para la octava semana, la cabeza es casi tan grande como el resto del cuerpo del embrión, y todas las estructuras cerebrales principales están en su lugar. Los genitales externos son evidentes, pero en este punto, los embriones masculinos y femeninos son indistinguibles. El hueso comienza a reemplazar el cartílago en el esqueleto embrionario a través del proceso de osificación. Al final del período embrionario, el embrión está a aproximadamente $3 \mathrm{~cm}$ (1.2 in) de la corona a la grupa y pesa aproximadamente $8 \mathrm{~g}(0.25 \mathrm{oz})$. La mayoría de estas investigaciones se centrarán en las primeras ocho semanas de vida (conocido como el período embrionario) cuando los sistemas de órganos se desarrollan. Trabajos adicionales presentan brevemente la maduración fetal, el parto y el neonato.

\section{Conclusiones.}

A medida que el cigoto viaja hacia el útero, experimenta numerosas divisiones en las que el número de células se duplica (blastómeros). Al llegar al útero, el conceptus se ha convertido en una esfera de células muy compacta llamada mórula, que luego se convierte en un blastocisto que consiste en una masa celular interna dentro de una cavidad llena de líquido rodeada de trofoblastos. Los implantes de blastocistos en la pared uterina, los trofoblastos se fusionan para formar un sincitiotrofoblasto, y el conceptus está envuelto por el endometrio. Se forman cuatro membranas embrionarias para soportar el embrión en crecimiento: el amnios, el saco vitelino, las alantoides y el corion. Las vellosidades coriónicas del corion se extienden hacia el endometrio para formar la porción fetal de la placenta. La placenta suministra oxígeno y nutrientes al embrión en crecimiento; También elimina el dióxido de carbono y otros desechos metabólicos. 


\section{Desarrollo embriológico humano}

Vol. 3, núm. 1., (2019)

Alicia Cumanda Solano Barona; Deborah Denisse Jaramillo Cañadas; Karen Gissela Moreira Cusme; Karym Gabriela Jácome Vera

Después de la implantación, las células embrionarias se someten a una gastrulación, en la cual se diferencian y se separan en un disco embrionario y establecen tres capas germinales primarias (el endodermo, el mesodermo y el ectodermo). A través del proceso de plegamiento embrionario, el feto comienza a tomar forma. La neurulación inicia el proceso de desarrollo de estructuras del sistema nervioso central y la organogénesis establece el plan básico para todos los sistemas de órganos.

\section{Bibliografía.}

Alarcon, V., \& Marikawa, Y. (2003). Unbiased contribution of the first two blastomeres to mouse blastocyst development. Mol Reprod Dev, 72(3), 354-61.

Barron, D. (1944). The foetal circulation and its changes at birth in some small laboratory animals. J Physiol, 133(1), 202-212.

Flores, V. (2009). Embriología Humana. México: Panamericana.

Lagman, T. (2010). Embriología Médica. $11^{\circ}$ edición.

Larsen, W. (2001). Human Embryology .

Moore, K. (2001). The Developing Human: Clinically Oriented Embryology.

O‘Malley, C., \& Saunders, J. (1982). Leonardo da Vinci on the human body.

Polin, R. (1999). Fisiologia fetal y neonatal.

Scott, L. (2003). Pronuclear scoring as a predictor of embryo development. Reprod Biomed Online, 6(2), 201-214. 